\title{
Plantas de Cobertura de Solo como Hospedeiras Alternativas DE Colletotrichum guaranicola ${ }^{1}$
}

\author{
Cover Crops as Intermediate Hosts to Colletotrichum guaranicola
}

\author{
MILEO, L.J. ${ }^{2}$, BENTES, J.L.S. ${ }^{3}$, SILVA, J.F. ${ }^{3}$ e CHRISTOFFOLETI, P.J. ${ }^{4}$
}

\begin{abstract}
RESUMO - As plantas de cobertura de solo usadas para suprimir o crescimento de plantas daninhas podem hospedar fungos fitopatogênicos. Para testar essa hipótese, elaborou-se este trabalho com o objetivo de avaliar o comportamento de nove espécies de plantas como possíveis hospedeiras do fungo Colletotrichum guaranicola. O experimento foi conduzido em casa de vegetação sob delineamento inteiramente casualizado, com quatro repetições. Cada vaso com três plantas da mesma espécie representou uma unidade experimental. As espécies que constituíram os tratamentos foram: Arachis pintoi, Calopogonium mucunoides, Chamaecrista rotundifolia, Crotalaria striata, Desmodium ovalifolium, Flemingia congesta, Mucuna aterrima, Pueraria phaseoloides e Tephrosia candida. Quarenta dias após a semeadura, as plantas foram inoculadas com suspensão de esporos de C. guaranicola na concentração de $10^{5}$ conídios $\mathrm{mL}^{-1}$, enquanto as plantas testemunhas receberam somente água. As plantas foram mantidas em câmara úmida por 48 horas. Diariamente, foram feitas observações por 15 dias após a inoculação, para visualizar sintomas da doença. As espécies que não apresentaram sintomas de C. guaranicola foram Arachis pintoi, Chamaecrista rotundifolia, Desmodium ovalifolium, Flemingia congesta e Tephrosia candida, e as que manifestaram sintomas após a inoculação foram Calopogonium mucunoides, Crotalaria striata, Mucuna aterrima e Pueraria phaseoloides, que podem ser fontes de inóculo do patógeno da antracnose para o guaranazeiro.
\end{abstract}

Palavras-chave: antracnose do guaranazeiro, hospedeira alternativa, leguminosas.

\begin{abstract}
Cover crops used to suppress weed growth can be intermediate hosts to phytopathogenic fungi. To test this hypothesis, nine species of cover crops were evaluated as hosts to Colletotrichum guaranicola. The experiment was arranged in a randomized design, with four replicates, and conducted under greenhouse conditions. Each vase with three plants of one species constituted one plot. The species treated were: Arachis pintoi, Calopogonium mucunoides, Chamaecrista rotundifolia, Crotalaria striata, Desmodium ovalifolium, Flemingia congesta, Mucuna aterrima, Pueraria phaseoloides and Tephrosia candida. Forty days after sowing, the plants were inoculated with spores of C. guaranicola at a concentration of $10^{5}$ conidia/ $\mathrm{mL}$, while the control plants received only water. The plants were then kept in a humid chamber for 48 hours. Daily observations were made to search for symptoms during 15 days after inoculation. The species that did not present symptoms of C. guaranicola were Arachis pintoi, Chamaecrista rotundifolia, Desmodium ovalifolium, Flemingia congesta and Tephrosia candida and those that did were Calopogonium mucunoides, Crotalaria striata, Mucuna aterrima and Pueraria phaseoloides, being a potential source of inoculation of the pathogen anthracnose for the guarana plant.
\end{abstract}

Keywords: guarana plant anthracnose, intermediate host, leguminous plants.

Recebido para publicação em 3.2.2006 e na forma revisada em 10.11.2006.

Prof $^{a}$. Assistente, M.S., Faculdade de Ciências Agrárias, Universidade Federal do Amazonas - UFAM, Campus Universitário, Av. Rodrigo Octavio J. Ramos, 3000, 69077-00 Manaus-AM. ${ }^{3}$ Professores Adjuntos, D.S. - UFAM, <jfsilva@ufam.edu.br>. ${ }^{4}$ Professor Associado do Departamento de Produção Vegetal - ESALQ/USP, <pjchrist@esalq.usp.br>, Caixa Postal 09, 13419-900 Piracicaba-SP. 


\section{INTRODUÇÃO}

As plantas de cobertura de solo têm sido usadas como alternativa no manejo das plantas daninhas em cultivos de banana (Musa sp.) (Espindola et al., 2000), citros (Dalcomo et al., 1999), entre outros. Essas plantas, além de suprimirem o crescimento das plantas daninhas, melhoraram a qualidade física, química e biológica do solo onde foram cultivadas (Canto, 1992).

O uso de leguminosas nos sistemas de produção do guaranazeiro para suprimir infestações de plantas daninhas pode ser uma opção para o produtor, devido ao baixo custo de implantação e manejo. Entretanto, algumas espécies de plantas podem apresentar-se como hospedeiras alternativas ao Colletotrichum guaranicola, agente da antracnose do guaranazeiro, a principal doença desta cultura, tendo sido apontada como um dos fatores da redução da área cultivada de guaraná no Estado do Amazonas (IBGE, 1999).

Algumas espécies de plantas leguminosas são hospedeiras de fungos do gênero Colletotrichum. Assim, Mucuna aterrima, entre quatro espécies de leguminosas semeadas em experimento de campo cultivado com guaraná, propiciou alto índice de antracnose nas plantas de guaranazeiro (Fernandes, 2003), ao passo que em Mucuna cochinchinesis, também semeada em guaranazal, não foram observados sintomas dessa doença (Canto, 1992). Já em estilosantes, uma leguminosa forrageira, encontrou-se o fungo C. gloeosporioides, que desfolha e destrói completamente essa planta (Verzignassi \& Fernandes, 2001). Outras leguminosas, como Aschynomene, Arachis, Cassia, Centrosema, Desmodium, Lablab, Leucaena e Macroptilium, também foram suscetiveis aos fungos C. gloeosporioides e C. truncatum (Lenné, 1990).

Neste trabalho, objetivou-se avaliar nove espécies de plantas de cobertura de solo como possiveis hospedeiras alternativas do patógeno C. guaranicola.

\section{MATERIAL E MÉTODOS}

O experimento foi realizado no período de julho de 2004 a abril de 2005, em casa de vegetação, sendo repetido por três vezes, na área de produção da Universidade Federal do Amazonas, Manaus-AM.

O delineamento experimental foi inteiramente ao acaso, sendo cada parcela constituída por um vaso com três plantas da mesma espécie, com quatro repetições. Os tratamentos foram as seguintes espécies: Arachis pintoi, Calopogonium mucunoides, Chamaecrista rotundifolia, Crotalaria striata, Desmodium ovalifolium, Flemingia congesta, Mucuna aterrima, Pueraria phaseoloides e Tephrosia candida.

As sementes de C. rotundifolia, C. striata, D. ovalifolium, F. congesta, C. mucunoides e P. phaseoloides foram escarificadas com soda cáustica (Embrapa, 1982). No plantio de A. pintoi foram usados estolões com $10 \mathrm{~cm}$ de comprimento e três internódios.

O substrato foi "terriço" de floresta seco e peneirado, para uniformização. Amostras foram retiradas para análise, obtendo-se os seguintes resultados: $24,82 \%$ de areia total, $3,32 \%$ de silte e $71,86 \%$ de argila. A composição química apresentou $\mathrm{pH}$ (em água 1:2,5) $=4,00 ; \mathrm{Al}^{3+}=2,80 \mathrm{cmol}_{\mathrm{C} \mathrm{kg}}{ }^{-1} ; \mathrm{H}^{+}+\mathrm{Al}^{3+}=$ $15,10 \mathrm{cmol}_{\mathrm{C}} \mathrm{kg}^{-1} ; \mathrm{Ca}^{2+}=0,30 \mathrm{cmol}_{\mathrm{C}} \mathrm{kg}^{-1} ; \mathrm{Mg}^{2+}$ $=0,00 \mathrm{cmol}_{\mathrm{C} \mathrm{kg}} \mathrm{kg}^{-1} \mathrm{~K}=34,00 \mathrm{mg} \mathrm{kg}^{-1} ; \mathrm{P}=$ $1,0 \mathrm{mg} \mathrm{kg}^{-1}$; matéria orgânica $=52,96 \mathrm{~g} \mathrm{~kg}^{-1}$; $\mathrm{CTC}=37,10 ;$ e $\mathrm{V}(\%)=71,20$. Em cada vaso com capacidade de $5 \mathrm{~kg}$ foram colocados $4 \mathrm{~kg}$ de terriço e aplicados 17,810 g de calcário, para correção da acidez do substrato. Trinta e sete dias após, foram aplicados 0,618 g de superfosfato triplo e 0,380 g de cloreto de potássio em cada vaso e, em seguida, fez-se a semeadura das plantas e o plantio dos estolões de A. pintoi. Após quarenta dias de idade, todas as plantas foram inoculadas.

Para isolar o patógeno - Colletotrichum guaranicola - foram coletadas amostras de folhas de guaranazeiro com sintomas típicos de antracnose, no plantio experimental de guaraná da Embrapa, em Manaus. No laboratório, os fragmentos foliares foram desinfestados superficialmente (Dhingra \& Sinclair, 1995) e isolados em placas de Petri com meio de cultura BDA (Batata-Dextrose-Ágar) acrescido de antibiótico clorafenicol (250 $\mathrm{mg} \mathrm{L}^{-1}$ ), para individualização das colônias do fungo e obtenção de culturas puras. Estas foram armazenadas em tubos de ensaio com BDA. 
A fim de estimular a produção dos esporos, as placas com os fungos foram expostas à luz fluorescente de $180 \mu \mathrm{mol} \mathrm{s}^{-1} \mathrm{~m}^{-2}$ constante, durante sete dias. Para confirmar a espécie do fungo (Postulados de Koch) foram medidos os esporos, com auxílio de uma ocular micrométrica acoplada a microscópio estereoscópico. Os dados médios de comprimento e largura dos esporos foram comparados com os parâmetros indicados na literatura (Bentes \& Barreto, 2004).

O preparo do inóculo foi feito adicionandose $20 \mathrm{~mL}$ de água destilada às placas contendo as colônias de C. guaranicola, que foram levemente raspadas para liberação dos esporos e preparo da suspensão. A concentração da suspensão de esporos foi ajustada para $10^{5}$ conídios $\mathrm{mL}^{-1}$, com o auxílio de câmara de Neubauer.

A inoculação foi feita, por meio de pulverização manual (borrifador), nas faces abaxial e adaxial das folhas de cada espécie e em 12 testemunhas de cada tratamento, com água destilada e esterilizada. Em seguida, as plantas foram mantidas em câmara úmida confeccionada com plástico transparente e umedecidas, por 48 horas. Após esse período, as leguminosas foram avaliadas diariamente, observandose em cada planta o surgimento de manchas foliares semelhantes aos sintomas da antracnose, durante 15 dias.

Foi feito o reisolamento do patógeno a partir das folhas lesionadas das espécies de leguminosas em meio de cultura BDA acrescido do antibiótico clorafenicol (250 $\left.\mathrm{mg} \mathrm{L}^{-1}\right)$ em ambiente de laboratório.

\section{RESULTADOS E DISCUSSÃO}

Das nove espécies avaliadas, Arachis pintoi, Chamaecrista rotundifolia, Desmodium ovalifolium, Flemingia congesta e Tephrosia candida não mostraram sintomas de antracnose causada por C. guaranicola. As leguminosas Calopogonium mucunoides, Crotalaria striata, Mucuna aterrima e Pueraria phaseoloides apresentaram sintomas de mancha foliar após a inoculação com o patógeno, demonstrando ser hospedeiras em potencial para o fungo, em razão de este ter sido reisolado das folhas com manchas foliares.
A suscetibilidade das leguminosas ao patógeno parece estar relacionada com os mecanismos de defesa de cada espécie, devido às diferentes reações das plantas inoculadas, já que algumas espécies apresentaram sintomas da doença após a inoculação e outras não, durante o período de avaliação (Tabela 1). A patogenicidade de isolados de fungos fitopatogênicos está relacionada com o genótipo do hospedeiro e com os fatores do ambiente (Dodd et al., 1992).

Quanto ao surgimento das lesões foliares nas espécies que hospedaram o fungo, foi observada pouca diferença em relação ao tempo para a reprodução dos sintomas da antracnose. Em calopogônio e crotalária, foram encontradas manchas foliares a partir do terceiro dia em algumas plantas; ao final da avaliação, todas as plantas inoculadas apresentaram folhas lesionadas. Em mucuna-preta e puerária, os primeiros sintomas apareceram a partir do quarto dia em algumas plantas, aumentando gradativamente o número de plantas com folhas lesionadas (Figura 1).

As diferenças temporais para o surgimento dos sintomas em cada espécie podem estar relacionadas ao período de latência, o qual corresponde ao tempo decorrido entre a inoculação e o desenvolvimento dos sintomas pelo patógeno (Amorim, 1995). Esse autor comenta também que curtos períodos de latência indicam relação compatível entre fatores, como hospedeiro suscetivel, patógeno agressivo e ambiente favorável.

Os sintomas desenvolvidos pelas plantas em função da ação de C. guaranicola possivelmente estejam associados às características bioquímicas e estruturais das folhas. Considerando que a antracnose é causada por um fungo com penetração direta nas células epidérmicas, a anatomia foliar apresenta-se como um dos fatores na interação patógenohospedeiro (Jerba et al., 2005).

A patogênese depende da resposta tigmotrópica do patógeno no reconhecimento da planta hospedeira, podendo esta resposta ser induzida pela superfície foliar (Jiménez-Diaz, 1996). Por exemplo, as nervuras mais salientes de feijoeiro atuaram como um estímulo físico ao tubo germinativo do agente da antracnose (Sovamilla \& Prestes, 1999). De modo geral, a 
Tabela 1 - Número de leguminosas inoculadas com o fungo Colletotrichum guaranicola que apresentaram lesão foliar

\begin{tabular}{|c|c|c|c|}
\hline \multirow{2}{*}{ Espécie de leguminosas } & $1^{\underline{a}}$ inoculação & $2^{\underline{a}}$ inoculação & $3^{\underline{a}}$ inoculação \\
\cline { 2 - 4 } & \multicolumn{2}{|c|}{$\mathrm{N}^{\mathrm{o}}$ de plantas inoculadas/No de plantas com sintomas } \\
\hline Arachis pintoi & - & $12 / 00$ & $12 / 00$ \\
\hline Calopogonium mucunoides & $09 / 00$ & $12 / 09$ & $12 / 12$ \\
\hline Chamaecrista rotundifolia & - & $12 / 00$ & $12 / 00$ \\
\hline Crotalaria striata & $09 / 03$ & $12 / 09$ & $12 / 12$ \\
\hline Desmodium ovalifolium & - & $12 / 00$ & $12 / 00$ \\
\hline Flemingia congesta & $09 / 00$ & $12 / 00$ & $12 / 00$ \\
\hline Mucuna aterrima & $09 / 09$ & $12 / 12$ & $12 / 12$ \\
\hline Pueraria phaseoloides & $09 / 03$ & $12 / 06$ & $12 / 12$ \\
\hline Tephrosia candida & $09 / 00$ & $12 / 00$ & $12 / 00$ \\
\hline
\end{tabular}
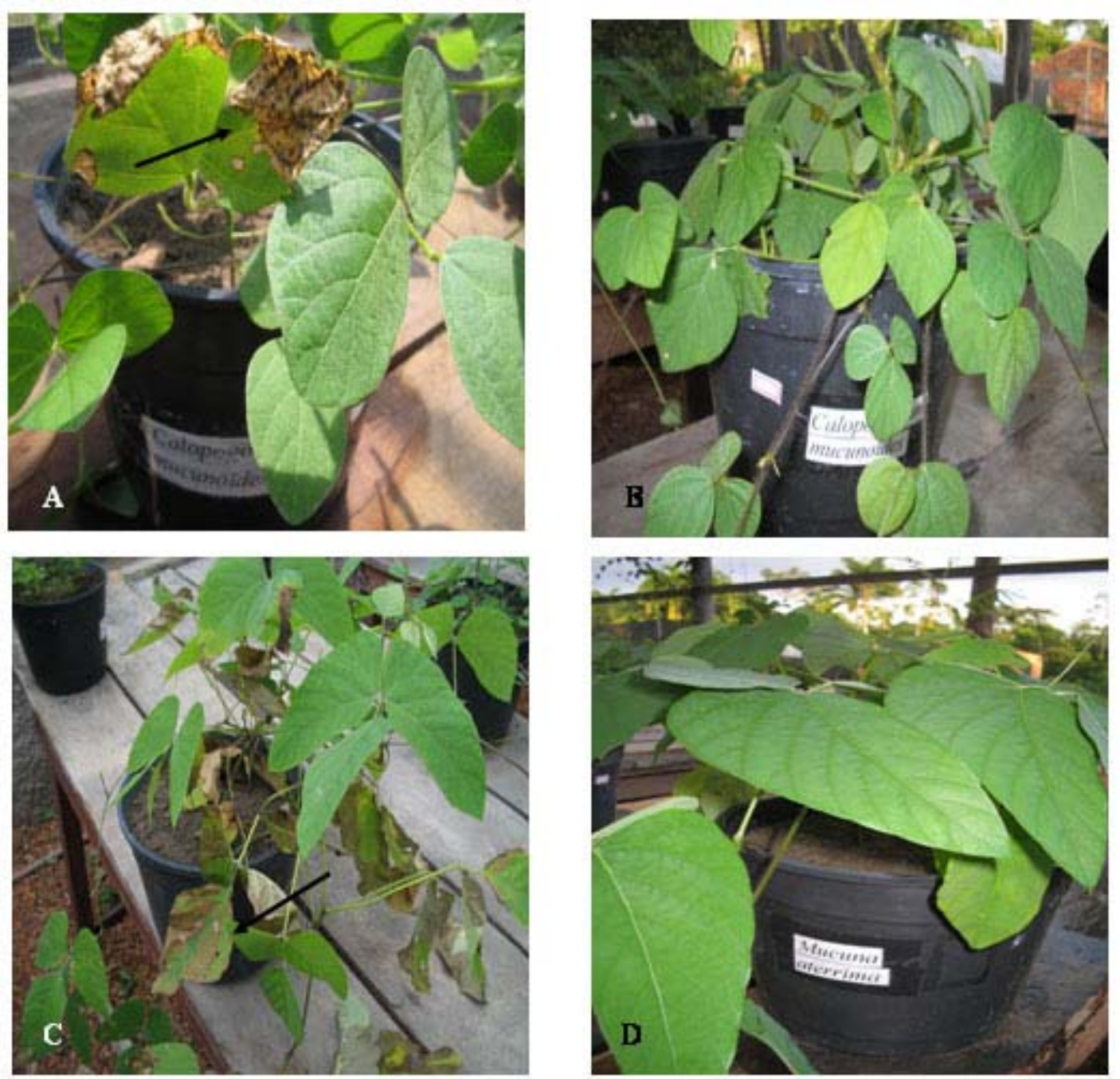

Figura 1 - Sintomas visuais de Colletotrichum guaranicola em folhas de calopogônio e mucuna-preta inoculadas (A, C) e testemunhas (B, D), respectivamente. 
pilosidade da folha reduz o contato do patógeno com a planta hospedeira (Pascholati \& Leite, 1995) e evita a formação do filme de água, necessário à germinação fúngica (Agrios, 1997).

Quanto à forma das lesões, as mais expressivas foram encontradas nas folhas de calopogônio e mucuna-preta. Houve semelhança entre a forma e a distribuição das lesões nas duas espécies. Inicialmente, as lesões apresentaram-se pequenas e regulares, de coloração marrom-clara. Ao final do período de 15 dias, foi verificado o coalescimento de muitas lesões, as quais se tornaram necróticas e de tonalidade marrom-escura. Em calopogônio, as lesões se concentraram no ápice da folha, enquanto na mucuna-preta, onde os sintomas foram mais agressivos, estas se tornaram alongadas, extensas e irregulares, distribuindo-se por quase toda a folha. A expansão da lesão reflete a ação infecciosa do patógeno (Berger et al., 1997). Isso sugere maior ação de C. guaranicola sobre a mucunapreta, quando comparada com as outras leguminosas.

O processo de colonização da folha pelo patógeno resultou em alteração de coloração, redução da área foliar e secamento dos folíolos. Na mucuna-preta - a leguminosa mais afetada - houve desfolha na maioria das plantas. As alterações na coloração das folhas afetam as trocas gasosas e, por conseguinte, o crescimento e a produção, devido ser a folha a principal fonte de assimilados para a planta (Magalhães et al., 2001).

A agressividade de C. guaranicola sobre as espécies estudadas foi evidenciada pela quantidade de folhas por planta que apresentaram lesões necróticas e pelo aumento da área necrosada, principalmente em calopogônio e mucuna-preta. Possivelmente, em campo, as leguminosas com antracnose seriam facilmente identificadas, assim como ocorreu em casa de vegetação. Em cultivos de guaranazeiro, as plantas com antracnose foram facilmente distinguidas, em conseqüência da coloração escura acentuada causada pelo patógeno, oferecendo um nítido contraste com o verde normal das folhas, permitindo que a planta doente fosse logo identificada (Duarte et al., 1995).

A presença do patógeno nas plantas que manifestaram os sintomas de antracnose foi confirmada a partir do reisolamento do fungo retirado de folhas lesionadas, obedecendo, assim, aos Postulados de Koch. Isso confirmou que C. guaranicola foi o causador das lesões nas folhas de calopogônio, crotalária, mucunapreta e puerária. Por esse resultado, pode-se afirmar que as espécies infectadas tornam-se hospedeiras alternativas em potencial do patógeno.

A mucuna-preta também foi relatada como hospedeira de Fusarium oxysporium (Coelho Netto \& Dhingra, 1999) e como suscetivel a doenças (Duke, 1981; Thurstson, 1997). Plantas de puerária foram constatadas como hospedeiras do fungo C. gloeosporiodes (Lenné, 1990). Este mesmo fungo foi o causador de antracnose em espécies de estilosantes na Austrália (Irwin et al., 1984), na América tropical, na Ásia e na África (Lenné, 1986), sendo considerado como patógeno principal. O fungo $C$. truncatum também afetou espécies de puerária, mas como patógeno secundário (Lenné, 1990).

O uso das leguminosas que apresentaram suscetibilidade ao patógeno, em sistemas de produção de guaranazeiro, possivelmente comprometeria a função de plantas de cobertura e manejo de plantas daninhas, em virtude de estas espécies terem se comportado como hospedeiras alternativas ao agente da antracnose, podendo ter papel importante na sobrevivência de C. guaranicola, servindo como fonte de inóculo. Confirma isso os resultados encontrados por Fernandes (2003), segundo o qual em mucuna-preta, além do aparecimento da doença na leguminosa, houve alto índice de antracnose nas plantas de guaraná. Em condições de tempo seco, o vento é responsável pelo maior índice de inoculação que se processa no campo, ao espalhar grande quantidade de conídios pelo guaranazal (Albuquerque, 1961). No período chuvoso, a incidência da doença é favorecida pela elevação da umidade e disseminação pela chuva (Trindade \& Poltronieri, 1997). Assim, é possivel deduzir que o patógeno é capaz de garantir sua sobrevivência sob diferentes condições de ambiente.

C. guaranicola também foi relatado como hospedeiro nas plantas daninhas Achanthospermum australe, Amaranthus viridis, Centratherum punctatum, Croton lobatus, 
Dalechampia scandens, Marsypianthes chamaedrys, Physalis chamaedrys, Solanun subinerme, Stachytarpheta cayennensis e Trema micrantha, freqüentes em cultivos de guaranazeiro (Batista, 1984). A capacidade de o patógeno desenvolver-se em diferentes espécies de plantas possivelmente aumentaria a quantidade de inóculo e o número de plantas de guaraná com antracnose. Cabe salientar que se torna muito importante evitar a ocorrência dessas espécies em plantios de guaraná.

As leguminosas que não foram suscetíveis parecem não oferecer possíveis riscos como fonte de inóculo de C. guaranicola às plantas de guaranazeiro. Todavia, é necessário conhecer a resposta dessas leguminosas ao ataque do patógeno sob condições de campo, para confirmar que não podem ser hospedeiras alternativas.

Há necessidade de outros estudos que relatem a associação de fatores que predisponham as plantas ao patógeno, ligados às condições de cultivo ou à resistência ou suscetibilidade de plantas de cobertura. A combinação de aspectos que envolvem as interações plantapatógeno tem contribuído para o desenvolvimento de estratégias para o manejo de doenças de plantas.

Arachis pintoi, Chamaecrista rotundifolia, Desmodium ovalifolium, Flemingia congesta e Tephrosia candida não se mostraram suscetíveis a Colletotrichum guaranicola.

Calopogonium mucunoides, Crotalaria striata, Mucuna aterrima e Pueraria phaseoloides foram suscetíveis a C. guaranicola, apresentando-se como hospedeiras alternativas em potencial para o patógeno.

\section{AGRADECIMENTOS}

A Ana Lúcia Machado dos Santos e Bruce Patrick Osborne, pelo auxílio na revisão gramatical e do abstract, respectivamente.

\section{LITERATURA CITADA}

AGRIOS, G. N. How plants defend themselves against pathogens. In: AGRIOS, G. N. (Ed.). Planty pathology. 4.ed. Califórnia: Academic Press, 1997. p. 93-114.

ALBUQUERQUE, F. C. Antracnose do guaraná. Rio de Janeiro: Ministério da Agricultura, Serviço de Informação Agrícola, 1961. 22 p.
AMORIM, L. Colonização e peprodução. In: BERGAMIN FILHO, A.; KIMATI, H.; AMORIM, L. (Eds.). Manual de fitopatologia: princípios e conceitos. 3.ed. São Paulo: Agronômica Ceres, 1995. p. 309-323.

BATISTA, M. F. Plantas silvestres hospedeiras de Colletotrichum guaranicola. In: SIMPÓSIO BRASILEIRO DO GUARANÁ, 1., 1984, Manaus. Anais... Manaus: EMBRAPA-UEPAE de Manaus, 1984. p. 409-411.

BENTES, J. L. S.; BARRETO, R. W. Reavaliação taxonômica de Colletotrichum guaranicola Albuq. agente causal da antracnose do guaranazeiro. Acta Amaz., v. 34, p. 129-131, 2004.

BERGER, R. D.; BERGAMIN FILHO, A.; AMORIM, L. Lesion expansion as an epidemic component. Phytopathology, v. 87, p. 1005-1013, 1997.

CANTO, A. C. Avaliação de leguminosas de cobertura no Estado do Amazonas. R. Univer. Amaz., Série Ci. Agr., v. 1, p. 49-61, 1992.

COELHO NETTO, R. A.; DHINGRA, O. D. Hospedeiros de Fusarium oxysporium f. sp. phaseoli. Fitopatol. Bras., v. 24, p. 156-159, 1999.

DALCOMO, J. M.; ALMEIDA, D. L.; GUERRA, J. G. M. Avaliação de leguminosas perenes para cobertura de solo em pomar cítrico no município de Jerônimo Monteiro, ES. Seropédica: Embrapa-CNPAB, 1999. 8 p. (Comunicado Técnico, 36).

DHINGRA, O. D.; SINCLAIR, J. B. Basic plant pathology methods. 2.ed. Boca Raton: CRC, 1995. 434 p.

DODD, J. C.; ESTRADA, A.; JEGER, M. J. Epidemiology of Colletotrichum gloeosporiodes in tropics. In: BAILEY, J. A.; JEGER, M. J. (Eds.). Colletotrichum: biology, pathology and control. Wallingford: CAB International, 1992. p. 308325 .

DUARTE, M. L. R.; ALBUQUERQUE, F. C.; CORRÊA, M. P. F. Variações morfológicas e fisiológicas em isolamentos de Colletotrichum guaranicola. Fitopatol. Bras., v. 20, p. 141-144, 1995.

DUKE, J. A. Handbook of legumes of world economic importance. New York: Plenum Press, 1981. 345 p.

EMPRESA BRASILEIRA DE PESQUISA AGROPECUÁRIA - EMBRAPA. Gado de Corte. Métodos de escarificação de sementes de leguminosas forrageiras tropicais, 1982. 6 p. (Comunicado Técnico, 13).

ESPINDOLA, J. A. A. et al. Potencial alelopático e controle de plantas daninhas por leguminosas herbáceas perenes consorciadas com a bananeira. Seropédica: Embrapa-CNPAB, 2000. 8 p. (Comunicado Técnico, 47). 
FERNANDES, R. S. Controle de plantas daninhas com leguminosas de cobertura de solo, em diferentes densidades populacionais, em guaranazal (Paullinia cupana var. sorbilis (Mart.) Ducke) no município de Presidente Figueiredo, AM. 2003. 58 f. Dissertação (Mestrado em Ciências Agrárias) - Universidade Federal do Amazonas, Manaus, 2003.

\section{INSTITUTO BRAILEIRO DE GEOGRAFIA E} ESTATÍSTICA - IBGE. Censo agrícola de 1999.

Disponível em: <http://www.sidra.ibge.gov.br.>. Acesso em: 19 jan. 2005.

IRWIN, J. A. G.; CAMERON, D. F.; LENNÉ, J. M.

Response of stylosanthes to anthracnose. In: STACE, H. M.; EDYE, L. A. (Eds.). Biology and gronomy of stylosanthes. Melbourne: Academic Press, 1984. p. 395-410.

JERBA, V. F.; RODELLA, R. A.; FURTADO, E. L. Relação entre a estrutura foliar de feijoeiro e a pré-infecção por Glomerella cingulata f. sp. phaseoli. Pesq. Agropec. Bras., v. 40, p. 217-223, 2005.

JIMÉNEZ-DIAZ, R. M. Interacciones planta-hongo: mecanismos de infección, patogénesis y resistencia. In: YACER, G. et al. (Eds.). Palología vegetal. Valencia: Sociedad Española de Fitopatologia, 1996. p. 739-769.

LENNÉ, J. M. Recent advances in the understanding of anthracnose of stylosanthes in tropical America. In: INTERNATIONAL GRASSLANDS CONGRESS, 15., 1986, Kyoto. Proceedings... Kyoto: 1986. p. 773-775.
LENNÉ, J. M. Colletotrichum diseases of legumes. In: BAILEY, J. A.; JEGER, M. J. (Eds.). Colletotrichum: biologia, pathology and control. Wallingford. CAB International. 1990. p. 134-166.

MAGALHÃES, P. C. et al. Aspectos fisiológicos de plantas de milho infectadas por molicutes sob diferentes níveis de água no solo. R. Bras. Fisiol. Veg., v. 13, p. 293-301, 2001.

PASCHOLATI, S. F.; LEITE, B. Hospedeiros: mecanismos de resistência. In: BERGAMIN FILHO, A.; KIMATI, H.; AMORIM, L. (Eds.). Manual de fitopatologia: princípios e conceitos. 3.ed. São Paulo: Agronômica Ceres, 1995. p. $417-453$.

SOVAMILLA, L. L.; PRESTES, A. M. Identificação de patotipos de Colletotrichum lindemuthianum de algumas regiões do Rio Grande do Sul. Fitopatol. Bras., v. 24, p. 416-421, 1999.

THURSTON, H. D. Slash/Mulch systems: sustainable methods for tropical agriculture. Boulder: Westview Press, 1997. $197 \mathrm{p}$.

TRINDADE, D. R.; POLTRONIERI, L. S. Doenças do guaraná. In: KIMATI, H. et al. (Eds.). Manual de fitopatologia: doenças das plantas cultivadas. 3.ed. São Paulo: Agronômica Ceres, 1997. p. 459-462.

VERZIGNASSI, J. R.; FERNANDES, C. D. Doenças em forrageiras. Campo Grande: Embrapa Gado de Corte, 2001. 50 p. (Documento, 50). 